\title{
openheart NT-proBNP and postoperative heart failure in surgery for aortic stenosis
}

\author{
Huiqi Jiang, ${ }^{1,2}$ Farkas Vánky, ${ }^{1}$ Henrik Hultkvist, ${ }^{1}$ Jonas Holm, ${ }^{1}$ Yanqi Yang, ${ }^{1,2}$ \\ Rolf Svedjeholm ${ }^{\circ}$
}

\begin{abstract}
- Additional material is published online only. To view please visit the journal online (http://dx.doi.org/10.1136/ openhrt-2019-001063).
\end{abstract}

To cite: Jiang H, Vánky F, Hultkvist H, et al. NT-proBNP and postoperative heart failure in surgery for aortic stenosis. Open Heart 2019;6:e001063. doi:10.1136/

openhrt-2019-001063

Received 1 April 2019 Revised 22 April 2019 Accepted 26 April 2019

Check for updates

(c) Author(s) (or their employer(s)) 2019. Re-use permitted under CC BY-NC. No commercial re-use. See rights and permissions. Published by BMJ.

${ }^{1}$ Cardiothoracic and Vascular Surgery, Linköping University, Linkoping, Sweden

${ }^{2}$ Cardiothoracic Surgery, Sun Yat-sen University of Medical Sciences, Guangzhou, China

Correspondence to Dr Rolf Svedjeholm; rolf. svedjeholm@regionostergotland. se

\begin{abstract}
Objective Postoperative heart failure (PHF) after aortic valve replacement (AVR) for aortic stenosis (AS) may initially appear mild and transient but has serious longterm consequences. Methods to assess PHF are not well documented. We studied the association between $\mathrm{N}$-terminal pro-B-type natriuretic peptide (NT-proBNP) and PHF after AVR for AS.
\end{abstract}

Methods This is a prospective, observational, longitudinal study of 203 patients undergoing elective first-time AVR for AS. Plasma NT-proBNP was assessed at preoperative evaluation, the day before surgery, and the first (POD1) and third postoperative morning. A clinical endpoints committee, blinded to NT-proBNP results, used prespecified haemodynamic criteria to diagnose PHF. The mean follow-up was $8.6 \pm 1.1$ years.

Results No patient with PHF $(\mathrm{n}=18)$ died within 30 days after surgery, but PHF was associated with poor long-term survival (HR 3.01, 95\% Cl 1.45 to 6.21, $\mathrm{p}=0.003$ ). NTproBNP was significantly higher in patients with PHF only on POD1 (6415 (3145-11 220) vs 2445 (1540-3855) ng/L, $\mathrm{p}<0.0001)$. NT-proBNP POD1 provided good discrimination of PHF (area under the curve $=0.82,95 \% \mathrm{Cl} 0.72$ to $0.91, p<0.0001$; best cut-off $5290 \mathrm{ng} / \mathrm{L}$ : sensitivity $63 \%$, specificity $85 \%$ ). NT-proBNP P0D1 $\geq 5290 \mathrm{ng} / \mathrm{L}$ identified which patients with PHF carried a risk of poor long-term survival, and PHF with NT-proBNP POD1 $\geq 5290 \mathrm{ng} / \mathrm{L}$ emerged as a risk factor for long-term mortality in the multivariable Cox regression (HR $6.20,95 \% \mathrm{Cl} 2.72$ to $14.1, p<0.0001)$.

Conclusions The serious long-term consequences associated with PHF after AVR for AS were confirmed. NT-proBNP level on POD1 aids in the assessment of PHF and identifies patients at particular risk of poor long-term survival.

\section{INTRODUCTION}

Postoperative heart failure (PHF) or low cardiac output syndrome typically presents at weaning from cardiopulmonary bypass (CPB) or during the first hours after surgery and is associated with a high early mortality after coronary artery bypass surgery $(\mathrm{CABG}) .^{1}{ }^{2}$ Although PHF was associated with high postoperative mortality after aortic valve replacement (AVR) in a mixed high-risk cohort, our experience is that the serious consequences of PHF after AVR for aortic stenosis (AS)

\section{Key questions}

What is already known about this subject?

- Postoperative heart failure (PHF) that presents in the early course after cardiac surgery is the major cause of postoperative mortality after coronary artery bypass surgery.

- In contrast, PHF after aortic valve replacement (AVR) for aortic stenosis (AS) usually is mild and transient with a low early mortality, but the serious consequences for long-term survival become apparent within a few years.

- Methods to assess PHF are not well documented with regard to outcome.

- N-terminal pro-B-type natriuretic peptide (NTproBNP) is an established biomarker for heart failure and also a relevant marker for outcome in cardiac surgery.

What does this study add?

- This study confirms that PHF after first-time AVR for AS is associated with a poor long-term survival, although it may initially appear benign.

- The novel findings are that NT-proBNP level on the first postoperative day (POD1) provided good discrimination of PHF after AVR for AS and that the best cut-off level of NT-proBNP for PHF on POD1 $\geq 5290$ $\mathrm{ng} / \mathrm{L}$ ) identified patients at particular risk of poor long-term survival.

How might this impact on clinical practice?

- NT-proBNP level on POD1 aids in the assessment of PHF and identifies patients at particular risk of poor long-term survival.

become evident only after a few years. ${ }^{2}{ }^{3}$ We found PHF to be an independent risk factor for poor long-term survival and speculated that an episode of PHF unmasks a myocardial factor, possibly associated with diastolic function, responsible for poor long-term outcome. ${ }^{2}$ Although PHF usually is easily recognisable, methods to assess PHF with regard to outcome are not well documented. Therefore, markers that can be used for prediction and assessment of PHF would be desirable.

Natriuretic peptides, particularly N-terminal pro-B-type natriuretic peptide 
(NT-proBNP) and B-type natriuretic peptide (BNP), are established biomarkers for heart failure in cardiology practice. ${ }^{45}$ In cardiac surgery, both preoperative and postoperative levels of NT-proBNP and BNP have been associated with adverse outcomes, treatment with inotropes and mechanical circulatory support. ${ }^{6-11}$ In this prospective study, the NT-proBNP level was determined from the preoperative evaluation until 6 months after surgery in patients undergoing AVR for isolated AS. The primary aim was to investigate the association between NT-proBNP and PHF, and the secondary aim was to analyse the impact of PHF and NT-proBNP on long-term survival after AVR for AS.

\section{METHODS \\ Patients}

The University Hospital in Linköping is a tertiary referral hospital and the only centre for cardiac surgery in the south-east region of Sweden, serving a population of approximately one million. All patients in the south-east region of Sweden undergoing preoperative evaluation for aortic valve surgery between June 2008 and January 2013 were screened for this prospective observational study. ${ }^{12}$ The study population consisted of consecutive patients who provided written informed consent and were scheduled to undergo AVR for AS. Exclusion criteria were a lack of informed written consent, emergency procedures and active endocarditis. Patients were excluded if they underwent concomitant procedures, with the exception of a simultaneous supracoronary aortic graft that did not require circulatory arrest $(n=26)$ or tricuspid valve procedure $(n=5)$.

A total of 548 patients with aortic valve disease, eligible for an aortic valve intervention, were screened, and 462 patients were included in the original study at the preoperative evaluation. Patients with equally significant AS and aortic regurgitation $(n=5)$ or patients undergoing surgery for aortic regurgitation $(n=43)$, transcatheter aortic valve implantation (TAVI) $(\mathrm{n}=126)$, concomitant CABG $(n=75)$, concomitant mitral valve surgery $(n=5)$ or a concomitant maze procedure $(n=5)$ were excluded. A flow chart of the patients is shown in online supplementary figure 1 .

\section{Study design}

This was a prospective, observational, longitudinal cohort study investigating (1) the discrimination of perioperative NT-proBNP for PHF according to prespecified criteria in patients undergoing AVR for AS and (2) the impact of PHF and NT-proBNP on long-term survival after AVR for AS. Venous blood samples for NT-proBNP were obtained at five time points: preoperative evaluation (PREEV), the day before the index procedure (PREOP), on the morning of the first (POD1) and third postoperative day (POD3), and at the 6-month follow-up. NT-proBNP was measured with an electrochemiluminescence immunoassay on a Roche Elecsys 2010 automated platform
(Roche Diagnostics, Basel, Switzerland). The results were released from the laboratory when the trial was terminated. Further details about NT-proBNP analyses are given in the online supplementary methods.

Mixed venous oxygen saturation $\left(\mathrm{SvO}_{2}\right)$ was measured at weaning from CPB, 5 min after administration of protamine, on admission to the intensive care unit (ICU), the next postoperative morning and whenever warranted by the haemodynamic state. Arterial blood pressure, central venous pressure and pulmonary artery pressure were monitored continuously. Transoesophageal echocardiography was routinely used. Demographic and perioperative data were registered prospectively in a computerised institutional database (Carath V.5.4, Fujitsu). All fields were defined in a data dictionary. Mortality data were retrieved from the Swedish Civil Registry.

\section{Study endpoints}

The primary endpoint was PHF. The secondary endpoint was all-cause mortality during follow-up.

\section{Definitions}

The definition of PHF was a haemodynamic state when the cardiac output does not meet the systemic demand, despite correction of volume or vascular resistance. Mixed $\mathrm{SvO}_{2}$ in relation to systolic arterial blood pressure (SAP), not explained by anaemia, hypovolaemia or shivering, was used to define this haemodynamic state ${ }^{13-15}: \mathrm{SvO}_{2}$ $<50 \%$ and $\mathrm{SAP}<130 \mathrm{~mm} \mathrm{Hg} ; \mathrm{SvO}_{2}<55 \%$ and $\mathrm{SAP}<110$ $\mathrm{mm} \mathrm{Hg} ; \mathrm{SvO}_{2}<60 \%$ and $\mathrm{SAP}<90 \mathrm{~mm} \mathrm{Hg}$. Severe PHF was defined as PHF leading to death or an extended ICU stay ( $\geq 72$ hours) in patients requiring treatment with an intraaortic balloon pump or at least one inotropic agent with the following dosages $\geq 24$ hours after admission to the ICU: epinephrine $\geq 0.033 \mu \mathrm{g} / \mathrm{kg} / \mathrm{min}$, milrinone $\geq 0.375$ $\mu \mathrm{g} / \mathrm{kg} / \mathrm{min}$, dopamine $\geq 4 \mu \mathrm{g} / \mathrm{kg} / \mathrm{min}$, dobutamine $\geq 4$ $\mu \mathrm{g} / \mathrm{kg} / \mathrm{min}$ or levosimendan regardless of dose.

Definitions for acute kidney injury, postoperative stroke, postoperative myocardial infarction, patient prosthesis mismatch, moderate and severe left ventricular (LV) dysfunction, and diabetes mellitus are given in the online supplementary methods.

\section{Statistical analysis}

Categorical variables are presented as percentage (number). Continuous variables that were not normally distributed are expressed as median with IQR. Categorical data were compared with Fisher's exact test. For continuous variables not following a normal distribution, the Mann-Whitney U test and Wilcoxon signed-rank test were used, as appropriate. A receiver operating characteristic analysis was carried out to calculate the area under the curve (AUC) to evaluate the discrimination of NT-proBNP for PHF. Youden's Index was used for calculation of the best cut-off point with regard to sensitivity and specificity.

Risk factors and predictors for PHF were identified with backward conditional stepwise multivariable 
logistic regression. Hosmer-Lemeshow goodness-of-fit statistics were calculated for the final model. Clinically relevant variables for heart failure, known extracardiac confounders for NT-proBNP and all variables with a $p$ value $<0.25$ in the univariable analysis were tested in the multivariable model (online supplementary tables 1 and 2).

Survival curves were generated by means of KaplanMeier estimates, and differences in survival were compared with the log-rank test. Cox proportional hazards regression models were used to identify risk factors for mortality during follow-up. To avoid data loss, missing data were managed with pairwise deletion when possible. Analyses of sequential data over time were checked with analyses using listwise deletion to exclude conflicting results. A p value $<0.05$ was considered statistically significant; all $p$ values were two-sided. Statistical analyses were performed with SPSS Statistics V.23 for Windows and Statistica V.12.0 (StatSoft, Tulsa, Oklahoma).

\section{RESULTS}

There were a total of 203 consenting patients with AS undergoing first-time AVR with at least one available NT-proBNP level at the following time points: PREEV $(\mathrm{n}=195), \quad$ PREOP $\quad(\mathrm{n}=199), \quad$ POD1 $\quad(\mathrm{n}=192), \quad$ POD3 $(\mathrm{n}=186)$ and 6-month follow-up $(\mathrm{n}=181)$. The overall 30 -day mortality was $0.5 \%$. The preoperative, intraoperative and postoperative characteristics of all patients and those with and without PHF are presented in tables 1 and 2. Preoperatively, patients with PHF had a significantly higher proportion of moderate or severe LV dysfunction, congestive heart failure, renal dysfunction, pulmonary hypertension and higher European System for Cardiac Operative Risk Evaluation II score. Intraoperatively, they had longer CPB times and aortic cross-clamp times.

Of the 18 patients who fulfilled the study criteria for PHF, 2 had mild transient PHF that resolved without inotropes. Three patients developed severe PHF. No patient with PHF died within 30 days after surgery, but PHF was associated with a significantly longer ICU stay and ventilation time, more signs of myocardial injury, and renal dysfunction (table 2). Overall 30 patients $(15 \%)$ were treated with inotropes at some stage intraoperatively or postoperatively. Patients classified as having PHF had a significantly longer ICU stay and more signs of myocardial and renal injury than those treated with inotropes who did not fulfil the study criteria for PHF (online supplementary table 3 ).

\section{Perioperative NT-proBNP levels in relation to PHF}

The NT-proBNP level increased postoperatively in all patients, but this was significantly more pronounced on POD1 in patients with PHF versus those without PHF (6415 (3145-11220) vs 2445 (1540-3855) ng/L, $\mathrm{p}<0.0001$ ) (table 2, figure 1). The average peak level was recorded on POD1 in the PHF cohort and on POD3 in the cohort without PHF. The NT-proBNP level on POD1 demonstrated good discrimination for PHF (AUC 0.82, $95 \%$ CI 0.72 to $0.91, \mathrm{p}<0.0001)$. The best cut-off value of $5290 \mathrm{ng} / \mathrm{L}^{1}$ had a sensitivity of $63 \%$ and a specificity of $85 \%$ (figure 2). Poor discrimination was found preoperatively and later in the postoperative course (figure 2).

NT-proBNP POD1 level $\geq 5290 \mathrm{ng} / \mathrm{L}$ and plasma creatine kinase-MB isoenzyme POD1 $>50 \mu \mathrm{g} / \mathrm{L}$ emerged as significant predictors of PHF according to multivariable logistic regression (online supplementary table 1 ). Variables associated with PHF according to univariate analysis are given in online supplementary table 2 .

Patients with an NT-proBNP level $\geq 5290 \mathrm{ng} / \mathrm{L}$ on POD1 had a significantly longer ICU stay and more signs of myocardial and renal injury. None of these patients died within 30 days (online supplementary table 4).

\section{Long-term survival related to PHF and NT-proBNP}

The mean follow-up from the entry into the study was $8.6 \pm 1.1$ years (range $6.5-10.5$ years). During this period, there were 48 deaths. Cumulative survival was significantly impaired in patients with PHF and an NT-proBNP level $\geq 5290 \mathrm{ng} / \mathrm{L}$ on POD1 (figures 3 and 4). The cumulative survival in patients with PHF was impaired if the NT-proBNP level was $\geq 5290 \mathrm{ng} / \mathrm{L}$ on POD1 (figure 5). The unadjusted HR for PHF for long-term mortality was 3.01 (95\% CI 1.45 to $6.21, \mathrm{p}=0.003)$. The unadjusted HR for patients with an NT-proBNP level $\geq 5290 \mathrm{ng} / \mathrm{L}$ on POD1 for long-term mortality was 3.25 (95\% CI 1.77 to $5.97, \mathrm{p}<0.0001)$.

The unadjusted HR for patients having both PHF and an NT-proBNP level $\geq 5290 \mathrm{ng} / \mathrm{L}$ on POD1 for long-term mortality was 7.72 (95\% CI 3.53 to 16.9 , p<0.0001). In the multivariable Cox regression model, PHF with an NT-proBNP level $\geq 5290 \mathrm{ng} / \mathrm{L}$ on POD1 emerged as a predictor of long-term mortality (HR 6.20, 95\% CI 2.72 to 14.12, $\mathrm{p}<0.0001$ ), together with preoperative NT-proBNP, age and diabetes mellitus (table 3 ). The univariate HRs for other variables tested in the multivariable Cox regression are shown in online supplementary table 5 .

\section{DISCUSSION}

This prospective study confirms previous findings that PHF after first-time AVR for AS is associated with a poor long-term prognosis after an apparently benign initial course. The novel findings are that the NT-proBNP level on POD1 provided good discrimination of PHF in this cohort and that the best cut-off NT-proBNP level on POD1 ( $\geq 5290 \mathrm{ng} / \mathrm{L}$ ) identified patients at particular risk of poor long-term survival.

We have previously reported that postoperative mortality associated with PHF after AVR for AS is low compared with PHF after CABG and the serious consequences of PHF only become evident with time. ${ }^{2}$ In this study, none of the patients with PHF died early after surgery, but late mortality was high, in agreement with our previous study. ${ }^{2}$ In the early postoperative phase, PHF was associated with a longer ICU stay and ventilation 
Table 1 Preoperative and intraoperative characteristics of all patients and those with or without PHF

\begin{tabular}{|c|c|c|c|c|}
\hline & $\begin{array}{l}\text { All patients } \\
(\mathrm{N}=203)\end{array}$ & $\begin{array}{l}\text { With PHF } \\
(n=18)\end{array}$ & $\begin{array}{l}\text { Without PHF } \\
(\mathrm{n}=185)\end{array}$ & P value* \\
\hline Age (years) & $70(65-77)$ & 73 (69-78) & $70(64-76)$ & 0.23 \\
\hline Female gender & 50 (102) & $39(7)$ & $51(95)$ & 0.34 \\
\hline NT-proBNP PREEV (ng/L) & 390 (180-995) & $825(215-3030)$ & $380(180-905)$ & 0.08 \\
\hline NT-proBNP PREOP (ng/L) & $460(180-1120)$ & $960(170-3810)$ & 430 (180-1030) & 0.14 \\
\hline $\mathrm{BMI}\left(\mathrm{kg} / \mathrm{m}^{2}\right)$ & $27(24-30)$ & $26(24-31)$ & $27(24-30)$ & 0.68 \\
\hline Obesity $\left(\mathrm{BMI} \geq 30 \mathrm{~kg} / \mathrm{m}^{2}\right)$ & $28(56)$ & $28(5)$ & $28(51)$ & 1 \\
\hline $\mathrm{BSA}\left(\mathrm{m}^{2}\right)$ & $1.88(1.75-2.05)$ & $1.91(1.83-2.02)$ & $1.88(1.74-2.06)$ & 0.61 \\
\hline Haemoglobin (g/L) & 139 (129-147) & $132(113-143)$ & $139(130-148)$ & 0.048 \\
\hline $\mathrm{p}$-Creatinine $(\mu \mathrm{mo} / \mathrm{L})$ & 84 (71-99) & $100(81-113)$ & $82(70-98)$ & 0.007 \\
\hline eGFR $\left(\mathrm{mL} / \mathrm{min} / 1.73 \mathrm{~m}^{2}\right)$ & 68 (58-82) & $61(48-71)$ & 68 (59-82) & 0.015 \\
\hline p-Albumin (g/L) & $41(38-43)$ & $42(37-43)$ & $41(38-43)$ & 0.60 \\
\hline p-Cystatin C (mg/L) & $1.15(0.99-1.31)$ & $1.38(1.14-1.88)$ & $1.14(1.00-1.30)$ & 0.004 \\
\hline Diabetes & $15(30)$ & $11(2)$ & $15(28)$ & 1 \\
\hline Hypertension & $53(107)$ & $44(8)$ & 54 (99) & 0.47 \\
\hline COPD & $4(9)$ & $6(1)$ & $4(8)$ & 0.57 \\
\hline Dyspnoea & $75(152)$ & $89(16)$ & $74(136)$ & 0.25 \\
\hline Angina & $29(59)$ & $39(7)$ & $28(52)$ & 0.42 \\
\hline Syncope & $11(23)$ & $6 \%(1)$ & $12(22)$ & 0.7 \\
\hline Echocardiographic indication & $15(31)$ & $5(1)$ & $16(30)$ & 0.32 \\
\hline NYHA III-IV & $54(110)$ & $78(14)$ & $52(96)$ & 0.047 \\
\hline NYHA IV & $1(2)$ & $6(1)$ & $0.5(1)$ & 0.17 \\
\hline CHF & $11(23)$ & $33(6)$ & $9(17)$ & 0.009 \\
\hline $\mathrm{AMl}<90$ days & $0.5 \%(1)$ & 0 & $0.5(1)$ & 1 \\
\hline Moderate or severe LV dysfunction & $9(18)$ & $28(5)$ & $7(13)$ & 0.013 \\
\hline Severe LV dysfunction & $2(5)$ & $6(1)$ & $2(4)$ & 0.37 \\
\hline Pulmonary hypertension & $6(13)$ & $28(5)$ & $4(8)$ & 0.003 \\
\hline Additive EuroSCORE & $6(4-7)$ & $7(5-9)$ & $6(4-7)$ & 0.042 \\
\hline EuroSCORE II & $1.6(1.1-2.8)$ & $2.1(1.9-5.6)$ & $1.5(1.1-2.7)$ & 0.002 \\
\hline CPB time (min) & $91(79-106)$ & $106(96-160)$ & $89(79-104)$ & 0.001 \\
\hline Aortic cross-clamp time (min) & $66(58-78)$ & 77 (65-92) & $65(57-77)$ & 0.017 \\
\hline
\end{tabular}

Data given as median (IQR) or percentage $(\mathrm{n})$.

${ }^{*}$ PHF versus without PHF.

$\mathrm{AMI}$, acute myocardial infarction; BMI, body mass index; BSA, body surface area; CHF, congestive heart failure; COPD, chronic obstructive pulmonary disease; CPB, cardiopulmonary bypass; EuroSCORE, European System for Cardiac Operative Risk Evaluation; LV, left ventricular;MDRD formula, Modification of Diet in Renal Disease formula; NT-proBNP, N-terminal pro-B-type natriuretic peptide; NYHA, New York Heart Association functional classification;PHF, postoperative heart failure; PREEV, preoperative evaluation; PREOP, the day before index procedure; eGFR, estimated glomerular filtration rate according to MDRD formula; $p$, plasma.

time, more signs of myocardial injury, and renal dysfunction. Maganti et al reported a high early mortality associated with low cardiac output syndrome after AVR, but their study included all aortic valve procedures with a high proportion of emergency procedures, reoperations and endocarditis, with preoperative renal dysfunction and shock emerging as important risk factors. ${ }^{3}$ In our previous retrospective study, an unselected population of patients from south-eastern Sweden undergoing AVR for
AS for the first time were studied, and this prospective cohort only differed by including elective patients. ${ }^{2}$

A history of congestive heart failure, hypertension, pulmonary hypertension, severe systolic LV dysfunction, preoperative haemodynamic instability, intraoperative myocardial infarction and an extended aortic cross-clamping time were identified as risk factors for PHF after AS in our previous study. ${ }^{16}$ The current study did not include emergency patients, but in general the 
Table 2 Postoperative characteristics of all patients and those with or without PHF

\begin{tabular}{|c|c|c|c|c|}
\hline & $\begin{array}{l}\text { All patients } \\
(\mathrm{N}=203)\end{array}$ & $\begin{array}{l}\text { With PHF } \\
(n=18)\end{array}$ & $\begin{array}{l}\text { Without PHF } \\
(n=185)\end{array}$ & P value* \\
\hline NT-proBNP P0D1 (ng/L) & 2595 (1590-4065) & $\begin{array}{l}6415 \\
(3145-11220)\end{array}$ & $\begin{array}{l}2445 \\
(1540-3855)\end{array}$ & $<0.0001$ \\
\hline$\triangle N$ T-proBNP P0D1-PREOP (ng/L) & $1756(1080-2750)$ & $\begin{array}{l}3000 \\
(1580-6295)\end{array}$ & $\begin{array}{l}1726 \\
(1020-2590)\end{array}$ & 0.023 \\
\hline NT-proBNP POD3 (ng/L) & $3920(2590-6690)$ & $\begin{array}{l}5530 \\
(3370-8460)\end{array}$ & $\begin{array}{l}3840 \\
(2540-6210)\end{array}$ & 0.08 \\
\hline$\triangle$ NT-proBNP P0D3-PREOP (ng/L) & $3020(1871-4760)$ & $\begin{array}{l}2850 \\
(925-4320)\end{array}$ & $\begin{array}{l}3040 \\
(1891-4760)\end{array}$ & 0.58 \\
\hline 6-month follow-up NT-proBNP (ng/L) & $310(170-730)$ & $\begin{array}{l}340 \\
(260-2310)\end{array}$ & $\begin{array}{l}300 \\
(165-665)\end{array}$ & 0.08 \\
\hline PPM & $79(143 / 181)$ & $92(11 / 12)$ & $78(132 / 169)$ & 0.47 \\
\hline Ventilation time (hours) & $3(2-5)$ & $8(3-25)$ & $3(2-5)$ & $<0.0001$ \\
\hline Ventilation time $>48$ hours & $2(4)$ & $17(3)$ & $0.5(1)$ & 0.002 \\
\hline Postoperative stroke & $1(2)$ & - & $1(2)$ & 1 \\
\hline p-Troponin T POD3 (ng/L) & $290(201-467)$ & $725(414-838)$ & $272(189-430)$ & $<0.0001$ \\
\hline p-CK-MB P0D1 ( $\mu \mathrm{g} / \mathrm{L})$ & $18(13-25)$ & $30(19-58)$ & $17(13-24)$ & 0.002 \\
\hline p-CK-MB P0D1 > 50 $\mu \mathrm{g} / \mathrm{L}$ & $4(8)$ & $28(5)$ & $2(3)$ & $<0.0001$ \\
\hline PMI & $2(4)$ & $17(3)$ & $0.5(1)$ & 0.002 \\
\hline p-Cystatin C POD3 (mg/L) & $1.34(1.13-1.64)$ & $1.96(1.41-2.36)$ & $1.32(1.11-1.56)$ & $<0.0001$ \\
\hline
\end{tabular}

Data given as median (IQR) or percentage (n).

${ }^{*}$ PHF versus without PHF.

CK-MB, creatine kinase-MB isoenzyme; ICU, intensive care unit; NT-proBNP, N-terminal pro-B-type natriuretic peptide; p, plasma; PHF, postoperative heart failure; PMI, postoperative myocardial infarction; POD1, first postoperative day; POD3, third postoperative day; PPM, patient prosthesis mismatch; PREOP, the day before the index procedure.

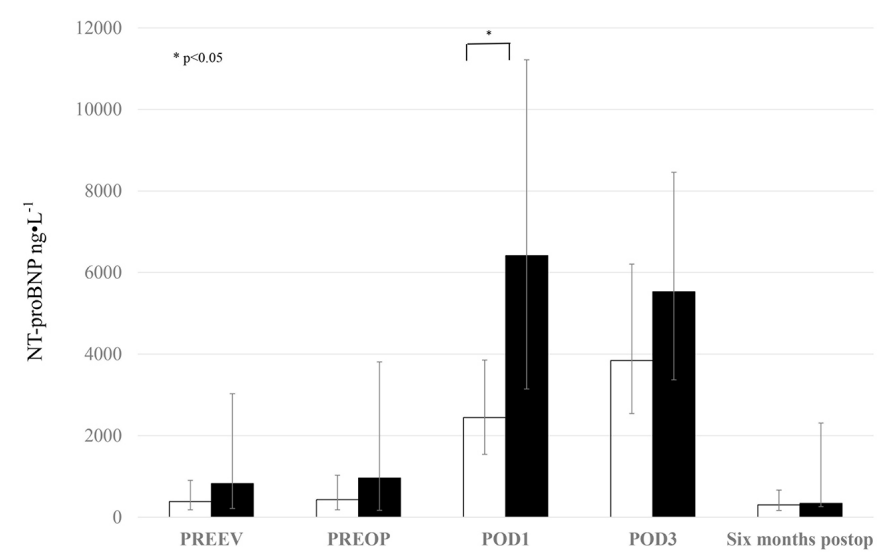

Figure 1 NT-proBNP levels (ng/L) before and after surgery in patients with PHF (black bars) and without PHF (white bars). Data are expressed as median with IQR; ${ }^{*} \mathrm{p}<0.05 .6$ months postop, 6-month follow-up; NT-proBNP, N-terminal pro-B-type natriuretic peptide; PHF, postoperative heart failure; POD1, first postoperative day; POD3, third postoperative day; PREEV, preoperative evaluation; PREOP, the day before the index procedure. results support these findings, as patients with PHF had a significantly higher proportion of moderate or severe LV dysfunction, preoperative congestive heart failure, pulmonary hypertension, postoperative myocardial infarction, and longer aortic cross-clamping time.

In cardiac surgery, both high preoperative and postoperative levels of natriuretic peptides have been associated with major cardiac events, treatment with inotropes, an extended ICU stay, ventricular dysfunction and mortality. ${ }^{6-11} 1718$ Similarly, the present study found patients with an NT-proBNP level on POD1 above the cut-off had significantly longer ICU stays, more signs of myocardial injury, higher incidences of renal injury and impaired long-term survival. In this study, only the NT-proBNP level on POD1 provided good discrimination for PHF. The reasons for the inconclusive results preoperatively and later in the postoperative course are unclear, and the results should be interpreted cautiously given the low number of events. However, in a recent study, the preoperative NT-proBNP level predicted PHF in patients undergoing CABG or surgery for mitral 


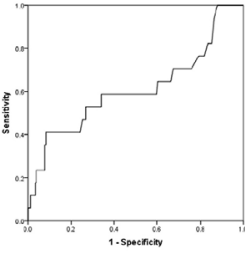

PREOP

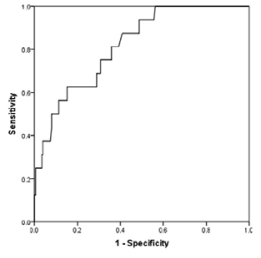

POD1

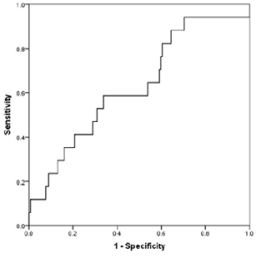

POD3
Figure 2 Discrimination of perioperative NT-proBNP for postoperative heart failure (PHF) in patients undergoing aortic valve replacement (AVR) for aortic stenosis (AS). According to receiver operating characteristic analyses, the NT-proBNP level on the first postoperative day (POD1) demonstrated good discrimination for PHF in patients undergoing AVR for AS (area under the curve (AUC) $=0.82,95 \% \mathrm{Cl} 0.72$ to 0.91 , $\mathrm{p}<0.0001$; best cut-off $5290 \mathrm{ng} / \mathrm{L}$ with a sensitivity of $63 \%$ and a specificity of $85 \%$ ), whereas the discrimination of NTproBNP for PHF was less convincing on the day before the index procedure (PREOP) and on the third postoperative day (POD3) (PREOP: AUC $=0.61,95 \% \mathrm{Cl} 0.44$ to $0.78, p=0.14$; POD3: $A \cup C=0.63,95 \% \mathrm{Cl} 0.49$ to $0.77, p=0.08$ ). NT-proBNP, $\mathrm{N}$-terminal pro-B-type natriuretic peptide.

valve regurgitation, whereas the predictive value was less convincing in patients undergoing surgery for AS. ${ }^{19} \mathrm{~A}$ possible reason is that a substantial proportion of PHF after AVR for AS occurs unexpectedly due to intraoperatively acquired myocardial dysfunction in low-risk patients. ${ }^{16}$

In our previous retrospective study, PHF emerged as an independent risk factor for long-term mortality after AVR for AS together with older age, preoperative renal dysfunction, procedure-associated stroke, body mass index $<19$ $\mathrm{kg} / \mathrm{m}^{2}$, preoperative atrial fibrillation and preoperative anaemia. ${ }^{2}$ This prospective study confirms the negative impact of PHF, older age and renal dysfunction on longterm survival after AVR for AS, and also suggests a role for diabetes mellitus. When we first reported the delayed serious consequences of PHF after AVR for AS, we speculated that an episode of PHF unmasks a myocardial factor responsible for the poor long-term outcome. The

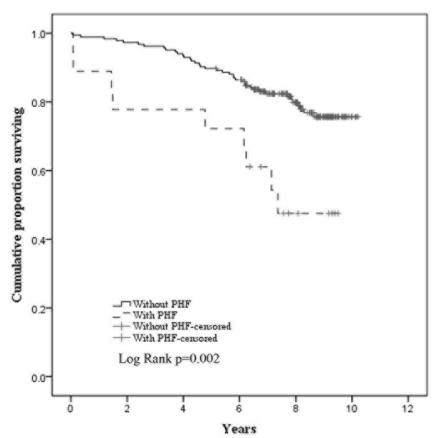

Patients at risk

\begin{tabular}{|l|l|l|l|l|l|l|l|l|l|l|l|}
\hline Year & 0 & 1 & 2 & 3 & 4 & 5 & 6 & 7 & 8 & 9 & 10 \\
\hline Without PHF & 185 & 183 & 180 & 178 & 173 & 166 & 159 & 123 & 89 & 43 & 3 \\
\hline PHF & 18 & 16 & 14 & 14 & 14 & 13 & 13 & 9 & 5 & 4 & \\
\hline
\end{tabular}

Figure 3 Cumulative survival (Kaplan-Meier) for patients with (dashed line) or without (solid line) postoperative heart failure (PHF).

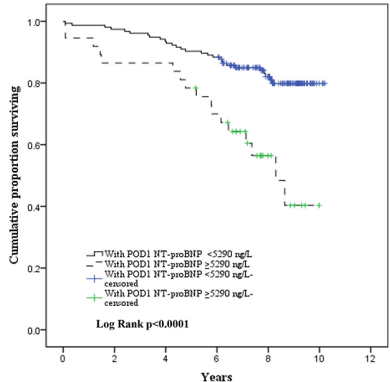

Patients at risk

\begin{tabular}{|l|l|l|l|l|l|l|l|l|l|l|l|}
\hline Year & 0 & 1 & 2 & 3 & 4 & 5 & 6 & 7 & 8 & 9 & 10 \\
\hline POD1 NT-proBNP $<5290 \mathrm{ng}^{-1} \mathbf{L}^{-1}$ & 155 & 153 & 151 & 149 & 145 & 140 & 137 & 107 & 81 & 40 & 3 \\
\hline POD1 NT-proBNP $\geq 5290 \mathbf{n g}^{-1} \mathbf{L}^{-1}$ & 37 & 35 & 32 & 32 & 32 & 29 & 25 & 18 & 8 & 4 & \\
\hline
\end{tabular}

Figure 4 Cumulative survival (Kaplan-Meier) for patients with an NT-proBNP level $\geq 5290 \mathrm{ng} / \mathrm{L}$ (dashed line) or $<5290$ $\mathrm{ng} / \mathrm{L}$ (solid line) on POD1. NT-proBNP, N-terminal pro-B-type natriuretic peptide; $\mathrm{POD} 1$, first postoperative day.

finding that NT-proBNP can identify which patients with PHF are at risk of poor long-term survival supports this assumption. As the previous and current study adjusted for systolic LV function, the myocardial factor may be related to myocardial fibrosis and diastolic function. ${ }^{2}$ The preoperative NT-proBNP level also emerged as a risk factor for long-term mortality, adding further support to the theory about an underlying myocardial factor, but the role of diastolic function for long-term survival after AVR for AS remains controversial and requires further investigation. $^{20}$

Natriuretic peptides can provide important additional information to clinical and echocardiographic evaluations. ${ }^{11}$ The role of natriuretic peptides in the early postoperative course after AVR for AS is supported by Nozohoor et al, who found that high BNP level on arrival to the ICU was an independent predictor of PHF after AVR. ${ }^{17}$ In our study the average peak level of NT-proBNP was recorded on POD1 in patients with PHF compared

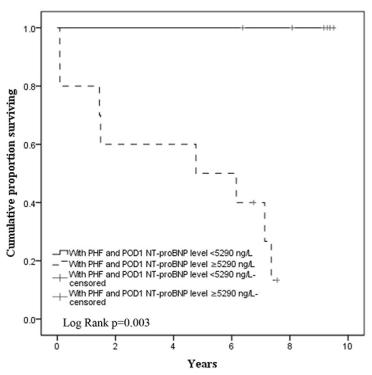

Patients at Risk

\begin{tabular}{|l|l|l|l|l|l|l|l|l|l|l|}
\hline Year & 0 & 1 & 2 & 3 & 4 & 5 & 6 & 7 & 8 & 9 \\
\hline PHF and PODI NT-proBNP $<5290 \mathrm{ng} \cdot \mathrm{L}^{-1}$ & 6 & 6 & 6 & 6 & 6 & 6 & 6 & 5 & 5 & 4 \\
\hline PHF and PODI NT-proBNP $\geq 5290 \mathrm{ng} \cdot \mathrm{L}^{-1}$ & 10 & 8 & 6 & 6 & 6 & 5 & 5 & 3 & & \\
\hline
\end{tabular}

Figure 5 Cumulative survival (Kaplan-Meier) in the subgroup with PHF for patients with an NT-proBNP level $\geq 5290 \mathrm{ng} / \mathrm{L}$ (dashed line) or $<5290 \mathrm{ng} / \mathrm{L}$ (solid line) on POD1. The NT-proBNP level on POD1 was missing in two patients (one died 6 years after surgery, the other one was alive 7 years after surgery). NT-proBNP, N-terminal pro-B-type natriuretic peptide; PHF, postoperative heart failure; POD1, first postoperative day. 
Table $3 \mathrm{HR}$ for long-term mortality in the multivariable regression model

\begin{tabular}{llc}
\hline Variable & HR $(\mathbf{9 5 \%}$ Cl) & P value \\
\hline $\begin{array}{l}\text { PHF with NT-proBNP P0D1 } \\
\geq 5290 \text { ng/L }\end{array}$ & $6.20(2.72$ to 14.1$)$ & $<0.0001$ \\
NT-proBNP PREOP $\geq 825$ ng/L & $2.80(1.48$ to 5.29$)$ & 0.002 \\
Age (years) & 1.07 (1.02 to 1.11$)$ & 0.002 \\
Diabetes mellitus & $2.42(1.22$ to 4.80$)$ & 0.011 \\
\hline
\end{tabular}

NT-proBNP, N-terminal pro-B-type natriuretic peptide; PHF, postoperative heart failure; POD1, first postoperative day; PREOP, the day before index procedure.

with POD3 in those without PHF. Thus, it seems plausible that natriuretic peptides, early after AVR for AS, best reflect the preoperative condition of the heart and myocardial dysfunction sustained during surgery. The current results show that an NT-proBNP level $\geq 5290$ ng/L on POD1 can help identify which patients with PHF after AVR for AS are at risk of poor long-term survival and require increased postoperative surveillance. This is important because the delayed consequences of PHF after AVR for AS may be almost equally profound in patients who were considered low-risk preoperatively. ${ }^{21}$

\section{Study limitations}

This study has limitations. The criteria used for the diagnosis of PHF in our study are inevitably questionable due to the lack of universally accepted criteria. PHF can be seen as a haemodynamic state when the cardiac output does not meet the systemic demand without supportive measures other than correction of volume or vascular resistance. However, cardiac output can be low even in patients with a completely normal postoperative course due to low systemic demands in anaesthetised patients early after cardiac surgery. ${ }^{22}$ We defined PHF by use of mixed $\mathrm{SvO}_{2}$, which reflects the balance between oxygen delivery and systemic oxygen demand, and is well documented with regard to outcome after cardiac surgery. ${ }^{13-15}$ Furthermore, well-known pitfalls such as shivering, anaemia and hypovolaemia were taken into account by the clinical endpoints committee. ${ }^{22}$ The outcome in patients with PHF, compared with those treated with inotropes who did not fulfil the criteria for PHF, suggests that the criteria used by the blinded endpoints committee identified the sickest patients (online supplementary table 3). Although this is one of the largest prospective cohort studies on PHF in surgical AVR patients, the major limitation is the low number of events. Some data, such as perioperative atrial fibrillation, that could influence postoperative NT-proBNP and long-term survival were not available. The strengths of this study are that it was a prospective observational study screening all patients undergoing evaluation for aortic valve disease over almost 5 years in the south-eastern region of Sweden. Furthermore, a homogeneous cohort of patients undergoing AVR for AS were studied, and patients having TAVI or surgery for aortic regurgitation were excluded due to different levels of natriuretic peptides both preoperatively and postoperatively. ${ }^{12}$

\section{CONCLUSION}

This study confirms that PHF after first-time AVR for AS is associated with a poor long-term prognosis, although it may initially appear benign. The NT-proBNP level obtained on POD1 provided good discrimination of PHF in this cohort, and an NT-proBNP level $\geq 5290 \mathrm{ng} / \mathrm{L}$ on POD1 identified which patients with PHF had an increased risk of poor long-term survival.

Acknowledgements The authors are grateful to Inger Huljebrant and Miriam Johansson for their excellent data collection and patient follow-up, and to Mats Fredriksson for assistance with statistical analyses.

Contributors $\mathrm{HJ}$ : data analysis, interpretation, initial drafting and final revision FV, HH, RS: concept, study design, data collection, interpretation, drafting and final revision. JH, YY: concept, interpretation, drafting and final revision. All authors reviewed and approved the final draft of this manuscript. They take full responsibility for all parts of this paper.

Funding Medical Research Council of Southeast Sweden FORSS (Grants 12657 23891, 159851, 311341) and County Council of Östergötland, Sweden (Grants LIO-610951, LIO 693091, LIO-796412).

\section{Competing interests None declared.}

Patient consent for publication Not required.

Ethics approval The study was approved by the Regional Ethical Review Board in Linköping (M 198-07, T 126-08, 2012/422-32). It was performed according to the Helsinki Declaration of Human Rights, and the patients were enrolled in the study after written informed consent was obtained.

Provenance and peer review Not commissioned; externally peer reviewed.

Data availability statement Data are available upon reasonable request.

Open access This is an open access article distributed in accordance with the Creative Commons Attribution Non Commercial (CC BY-NC 4.0) license, which permits others to distribute, remix, adapt, build upon this work non-commercially, and license their derivative works on different terms, provided the original work is properly cited, appropriate credit is given, any changes made indicated, and the use is non-commercial. See: http://creativecommons.org/licenses/by-nc/4.0/.

\section{REFERENCES}

1. O'Connor GT, Birkmeyer JD, Dacey LJ, et al. Results of a regional study of modes of death associated with coronary artery bypass grafting. Northern New England cardiovascular Disease Study Group. Ann Thorac Surg 1998;66:1323-8.

2. Vánky FB, Håkanson E, Svedjeholm R. Long-term consequences of postoperative heart failure after surgery for aortic stenosis compared with coronary surgery. Ann Thorac Surg 2007;83:2036-43.

3. Maganti MD, Rao V, Borger MA, et al. Predictors of low cardiac output syndrome after isolated aortic valve surgery. Circulation 2005;112(9 Suppl):1448-52.

4. Ponikowski P, Voors AA, Anker SD, et al. ESC guidelines for the diagnosis and treatment of acute and chronic heart failure: the task Force for the diagnosis and treatment of acute and chronic heart failure of the European Society of cardiology (ESC). developed with the special contribution of the heart Failure Association (HFA) of the ESC. Eur J Heart Fail 2016;2016:891-975.

5. Yancy CW, Jessup M, Bozkurt B, et al. 2017 ACC/AHA/HFSA focused update of the 2013 ACCF/AHA guideline for the management of heart failure: a report of the American College of Cardiology/American Heart Association Task Force on clinical practice guidelines and the heart failure Society of America. Circulation 2017;136:e137-61.

6. Reyes $\mathrm{G}$, Forés $\mathrm{G}$, Rodríguez-Abella $\mathrm{RH}$, et al. NT-proBNP in cardiac surgery: a new tool for the management of our patients? Interact Cardiovasc Thorac Surg 2005;4:242-7.

7. Fox AA, Shernan SK, Collard CD, et al. Preoperative B-type natriuretic peptide is as independent predictor of ventricular 
dysfunction and mortality after primary coronary artery bypass grafting. J Thorac Cardiovasc Surg 2008;136:452-61.

8. Cuthbertson BH, Croal BL, Rae D, et al. N-terminal pro-B-type natriuretic peptide levels and early outcome after cardiac surgery: a prospective cohort study. Br J Anaesth 2009;103:647-53.

9. Holm J, Vidlund M, Vanky F, et al. EuroSCORE II and N-terminal pro-B-type natriuretic peptide for risk evaluation: an observational longitudinal study in patients undergoing coronary artery bypass graft surgery. Br J Anaesth 2014:113:75-82.

10. Young Y-R, Sheu B-F, Li W-C, et al. Predictive value of plasma brain natriuretic peptide for postoperative cardiac complications $-A$ systemic review and meta-analysis. J Crit Care 2014;29:696.e1-696. e10.

11. Bergler-Klein J, Klaar U, Heger M, et al. Natriuretic peptides predict symptom-free survival and postoperative outcome in severe aortic stenosis. Circulation 2004;109:2302-8.

12. Hultkvist $\mathrm{H}$, Holm J, Svedjeholm R, et al. Rise and fall of NT-proBNP in aortic valve intervention. Open Heart 2018;5:e000739.

13. Svedjeholm R, Håkanson E, Szabó Z. Routine SvO2 measurement after CABG surgery with a surgically introduced pulmonary artery catheter. Eur J Cardiothorac Surg 1999;16:450-7.

14. Holm J, Håkanson E, Vánky F, et al. Mixed venous oxygen saturation predicts short- and long-term outcome after coronary artery bypass grafting surgery: a retrospective cohort analysis. $\mathrm{Br} J$ Anaesth 2011;107:344-50.
15. Holm J, Håkanson RE, Vánky F, et al. Mixed venous oxygen saturation is a prognostic marker after surgery for aortic stenosis. Acta Anaesthesiol Scand 2010;54:589-95.

16. Vánky FB, Håkanson E, Tamás E, et al. Risk factors for postoperative heart failure in patients operated on for aortic stenosis. Ann Thorac Surg 2006;81:1297-304.

17. Nozohoor S, Nilsson J, Lührs C, et al. B-type natriuretic peptide as a predictor of postoperative heart failure after aortic valve replacement. J Cardiothorac Vasc Anesth 2009;23:161-5.

18. Nozohoor S, Nilsson J, Algotsson L, et al. Postoperative increase in B-type natriuretic peptide levels predicts adverse outcome after cardiac surgery. J Cardiothorac Vasc Anesth 2011;25:469-75.

19. Jiang $\mathrm{H}$, Hultkvist $\mathrm{H}$, Holm J, et al. Impact of underlying heart disease per se on the utility of preoperative NT-proBNP in adult cardiac surgery. PLoS One 2018;13:e0192503.

20. Kampaktsis PN, Kokkinidis DG, Wong S-C, et al. The role and clinical implications of diastolic dysfunction in aortic stenosis. Heart 2017;103:1481-7.

21. Hultkvist $H$, Vánky F, Svedjeholm R. The combined impact of postoperative heart failure and EuroSCORE on long-term outcome after surgery for aortic stenosis. J Heart Valve Dis 2011;20:633-8.

22. Håkanson E, Svedjeholm R, Vanhanen I. Physiologic aspects in postoperative cardiac patients. Ann Thorac Surg 1995;59(2 Suppl):S12-S14. 